\title{
Gene Discovery and Gene Expression in the Rice Blast Fungus, Magnaporthe grisea: Analysis of Expressed Sequence Tags
}

\author{
Daniel J. Ebbole, ${ }^{1}$ Yuan Jin, ${ }^{1}$ Michael Thon, ${ }^{1}$ Huaqin Pan, ${ }^{2}$ Eric Bhattarai, ${ }^{1}$ Terry Thomas, ${ }^{3}$ and \\ Ralph Dean ${ }^{2}$ \\ ${ }^{1}$ Program for the Biology of Filamentous Fungi, Department of Plant Pathology \& Microbiology, Texas A\&M University, \\ College Station, U.S.A.; ${ }^{2}$ Fungal Genomics Laboratory, Center for Integrated Fungal Research, North Carolina State \\ University, Raleigh, U.S.A.; ${ }^{3}$ Department of Biology, Texas A\&M University, College Station, U.S.A.
}

Submitted 5 March 2004. Accepted 26 July 2004.

Over 28,000 expressed sequence tags (ESTs) were produced from cDNA libraries representing a variety of growth conditions and cell types. Several Magnaporthe grisea strains were used to produce the libraries, including a nonpathogenic strain bearing a mutation in the $P M K 1$ mitogen-activated protein kinase. Approximately 23,000 of the ESTs could be clustered into 3,050 contigs, leaving 5,127 singleton sequences. The estimate of 8,177 unique sequences indicates that over half of the genes of the fungus are represented in the ESTs. Analysis of EST frequency reveals growth and cell type-specific patterns of gene expression. This analysis establishes criteria for identification of fungal genes involved in pathogenesis. A large fraction of the genes represented by ESTs have no known function or described homologs. Manual annotation of the most abundant cDNAs with no known homologs allowed us to identify a family of metallothionein proteins present in M. grisea, Neurospora crassa, and Fusarium graminearum. In addition, multiply represented ESTs permitted the identification of alternatively spliced mRNA species. Alternative splicing was rare, and in most cases, the alternate mRNA forms were unspliced, although alternative $5^{\prime}$ splice sites were also observed.

Additional keyword: plant pathogen.

The rice blast fungus Magnaporthe grisea has been the subject of intensive investigation because of its tremendous economic and social impact as a plant pathogen as well as its genetic tractability (Valent and Chumley 1991). It has been used as a model for analysis of fungal avirulence genes and pathogenesis-related morphogenesis (Dean 1997; Howard and Valent 1996; Laugé and De Wit 1998; Tucker and Talbot 2001). Analysis of expressed sequence tags (ESTs) along with the recent availability of draft sequences of the genomes of plant pathogenic fungi provide the resources needed to simultaneously examine the full repertoire of mechanisms employed by pathogens during infection and colonization of their host. Previous studies have identified M. grisea ESTs expressed in planta (Kim et al. 2001) or have utilized serial analysis of gene expression (SAGE) (Irie et al. 2003) to identify $M$. grisea genes expressed during appressorium formation or in response to cAMP treatment.

Corresponding author: D. J. Ebbole; E-mail: d-ebbole@tamu.edu; Telephone: +1.979 .845 .4831 .
We have produced over 28,000 ESTs from nine different cDNA libraries and six different strains of $M$. grisea, resulting in an estimated 8,177 distinct singleton and contig sequences. The ESTs represent different stages of development, including conidia, mycelia, sexually developing colonies, and appressoria. The importance of the pmkl mitogen-activated protein (MAP) kinase for appressorium formation and invasive growth (Xu and Hamer 1996) led us to include a pmkl mutant strain as a source of cDNA clones for EST analysis. In addition, cultures grown on different nutrient sources (complete medium [cm], minimal medium, nitrogen starvation [ns] medium, rice cell walls $[\mathrm{cw}])$ were examined.

Identification of the genes, gene organization, and gene expression patterns in $M$. grisea are critical steps in functional genomic analysis of a plant pathogen. ESTs define genome segments as being expressed sequences and, therefore, serve as molecular identifiers of a gene. One example of gene discovery is the identification of a fungal-specific gene family encoding very small (22- to 28-residue) serine, threonine, and cysteine-rich metallothioneins. The cDNA sequence also defines introns, including documentation of the occurrence of alternative splicing. In addition, the relative abundance of ESTs provides a measure of gene expression. Our analysis of EST abundance defines a pattern of gene expression that appears to be diagnostic for genes involved in the early events in fungusplant interacttions.

\section{RESULTS}

EST sequence determination.

EST sequences were produced from nine different libraries (Table 1). A total of 28,682 sequences were identified as having high quality by Phred or by alignment to the genome sequence from 36,284 sequencing reactions (79\%). This total includes 119 clones that, based on alignment to the genome sequence, were clearly chimeric. Each of the chimeric sequences was split at the cloning junction to yield two EST sequences. After trimming for vector and poor quality segments, the average sequence length was 333 nucleotides (nt), and approximately $30 \%$ of the ESTs were longer than $400 \mathrm{nt}$, while $2.9 \%$ of sequences were shorter than $100 \mathrm{nt}$. As a second quality measure, we compared the EST sequences to the draft sequence of the $M$. grisea genome sequence. Approximately $95 \%$ of the ESTs were found to align with the genome sequence, using blastn (e value $=\mathrm{e}^{-15}$ ). The remaining sequences apparently fall within sequence gaps in the $M$. grisea genome sequences or are in the 
unassembled reads. Blastn alignments of EST sequences prior to trimming for quality scores were used as a second method for estimating EST sequence length. Trimming the EST length based on alignment to the $M$. grisea genome sequence yielded sequences that were, on average, $110 \mathrm{nt}$ longer than those trimmed based on quality scores. We used the sequences trimmed based on blastn alignments when possible and used quality scores to trim sequences that were not represented or were only partially represented in the genome sequence (sequences that overlapped ends of DNA sequence contigs).

\section{Analysis of sequences.}

ESTs were generated from several different libraries with the expectation that more unique genes would be identified from moderate levels of sequencing from diverse libraries rather than deep sequencing in a single library. The depth of sequencing was such that between 56 to $78 \%$ of the ESTs were found to reside within multisequence contigs for all of the libraries except for the appressorium (ap) library that was represented by only 410 sequences (Table 2). The combined ESTs for all libraries clustered into 3,050 multisequence contigs, with 5,127 singleton sequences yielding an estimate of 8,177 unique gene sequences. Neurospora crassa and $M$. grisea are both Sordariomycete fungi thought to have diverged roughly 50 to 150 million years ago (Berbee and Taylor 2001) and so are considered closely related to each other with respect to the vast evolutionary distance represented by the fungi. Based on automated annotation, it was estimated that approximately 10,000 proteins are encoded by $N$. crassa (Galagan et al. 2003). The genome size of $M$. grisea is similar to N. crassa, and the current version of automated annotation for the $M$. grisea genome predicts approximately 11,000 protein coding regions of greater than 100 residues. Thus, the 8,177-unigene set of clusters and singletons represents a signifycant fraction (70 to $80 \%$ ) of the total gene content of the rice blast fungus.

To characterize the uniqueness of each library, we assessed the relative number of library-specific sequences. The fraction of library-specific clones in each library ranged from 18 to $31 \%$. After clustering, 31 to $52 \%$ of the unique sequences (clusters plus singletons) in each library were found to be libraryspecific (Tables 2 and 3). A majority of unique sequences were singletons, and relatively few multisequence clusters were unique to each library. It is not possible to draw strong conclusions as to whether the genes represented by singletons are uniquely expressed in the specific conditions used to grow the cells for library construction or if they simply represent rare transcripts that would be found in other libraries with deeper sequence coverage. Overall 4,811 (59\%) of the unique sequences were represented in only one of the libraries.

The distribution of ESTs across multiple libraries was assessed as another measure of uniqueness of gene occurrence across libraries (Table 4). Relatively few multisequence clusters contain ESTs from clones representing all nine libraries. The majority of the clusters contain sequences found in one to three libraries, with the largest category being clusters represented by clones from two libraries. This pattern is mainly due to the fact that many of the multisequence contigs contain only a small number of ESTs. Considering only those clusters containing 30 or more ESTs, we found a shift toward genes being represented in multiple libraries. However, a significant fraction of clusters remain restricted to single or a small number of libraries, indicating real differences in gene expression patterns represented between libraries.

The ESTs were assigned functions according to gene ontology (GO) terms (Ashburner et al. 2000), and we examined the

Table 3. Library-specific expressed sequence tags (ESTs) and unique sequences

\begin{tabular}{lcc}
\hline Library description & $\begin{array}{c}\text { Library-specific } \\
\text { ESTs }(\%)^{\mathbf{a}}\end{array}$ & $\begin{array}{c}\text { Library-specific } \\
\text { unique genes }(\boldsymbol{\%})^{\mathbf{b}}\end{array}$ \\
\hline Appressorium & $119(29)$ & $104(31)$ \\
Complete medium & $909(28)$ & $606(41)$ \\
Conidiation & $606(18)$ & $510(33)$ \\
Rice cell wall & $1,053(27)$ & $570(45)$ \\
Pmk1 germling & $1,257(28)$ & $1,010(41)$ \\
Mating culture & $2,026(31)$ & $1,464(52)$ \\
Minimal medium & $297(20)$ & $242(29)$ \\
Nitrogen starved & $783(18)$ & $636(37)$ \\
Subtracted mycelium & $278(27)$ & $239(31)$ \\
Total & $7,328(26)$ & $4,811(59)$ \\
\hline
\end{tabular}

a $\%$ of total ESTs is shown in parentheses.

${ }^{\mathrm{b}}$ Clusters + singletons; \% total unique sequences is shown in parentheses.

Table 1. Libraries and tissue sources for sequences described in this study

\begin{tabular}{lcll}
\hline cDNA Library Name & Library ID & \multicolumn{1}{c}{ Strain } & \multicolumn{1}{c}{ Tissue/phase } \\
\hline Appressorium & $\mathrm{ap}$ & $70-15$ & Appressorium forming germlings \\
Complete medium & $\mathrm{cm}$ & Guy11 & Mycelium from yeast extract glucose culture \\
Conidiospore & $\mathrm{cs}$ & Guy11 & Conidia from oatmeal agar plate culture \\
Rice cell wall & $\mathrm{cw}$ & CP987 & Mycelium grown on rice cell walls \\
PMK1 mutant & $\mathrm{mk}$ & NN95 (Guy11) & Map kinase mutant germlings \\
Mating & $\mathrm{mt}$ & $4091-5-8+4136-4-3$ & Mixed culture undergoing mating \\
Mycelial & $\mathrm{my}$ & $70-15$ & Mycelium from minimal medium culture \\
Nitrogen starvation & $\mathrm{ns}$ & Guy11 & Mycelium from minimal medium with 6 hr nitrogen starvation \\
Subtracted & $\mathrm{su}$ & $\mathrm{P} 1.2$ & Mixed stress library with the 96 most abundant clones subtracted \\
\hline
\end{tabular}

Table 2. Statistics on clustering and redundancy within cDNA libraries

\begin{tabular}{|c|c|c|c|c|c|}
\hline cDNA library name & No. of ESTs & No. of ESTs in clusters (\%) & No. of clusters & Singletons $(\%)$ & Unique sequences (\%) \\
\hline Appressorium & 410 & $115(28)$ & 44 & $295(72)$ & $339(83)$ \\
\hline Complete medium & 3,193 & $2,100(66)$ & 398 & $1,093(34)$ & $1,491(47)$ \\
\hline Conidiospore & 3,405 & $2,296(67)$ & 431 & $1,109(33)$ & $1,540(45)$ \\
\hline Rice cell wall & 3,923 & $3,061(78)$ & 406 & $862(22)$ & $1,268(32)$ \\
\hline PMK1 mutant & 4,421 & $2,640(60)$ & 674 & $1,781(40)$ & $2,455(56)$ \\
\hline Mating & 6,521 & $4,690(72)$ & 959 & $1,831(28)$ & $2,790(43)$ \\
\hline Mycelial & 1,464 & $827(56)$ & 194 & $637(44)$ & $831(57)$ \\
\hline Nitrogen starvation & 4,310 & $3,046(71)$ & 473 & $1,264(29)$ & $1,737(40)$ \\
\hline Subtracted & 1,035 & $415(40)$ & 153 & $620(60)$ & $773(75)$ \\
\hline Combined & 28,682 & $23,555(82)$ & 3,050 & $5,127(18)$ & 8,177 (29) \\
\hline
\end{tabular}


representation of genes across functional categories (Table 5). In general, there was overall similarity in individual libraries for this general measure of functional categories. The most abundant categories represented proteins for cellular activities related to metabolism or physiological processes. These are primarily enzymes but also include a substantial number of putative DNA-binding proteins and transcription factors. A greater fraction of ESTs from the conidiospore (cs) library contained genes for cell growth, suggesting that mRNAs for rapid growth are stored in dormant spores. Alternatively, during harvesting the conidia may have become metabolically active prior to disruption for RNA extraction. A second finding was that the rice cell wall (cw) library had the highest percentages of clones categorized as extracellular. Closer inspection revealed that this difference is primarily due to the presence of ESTs with homology to enzymes involved in the breakdown of cellulose, xylan, and other plant cell wall components. In the $\mathrm{cw}$ library, 183 ESTs (4.7\%) encoded

Table 4. Distribution of sequences in multiple cDNA libraries

\begin{tabular}{lc}
\hline Libraries represented & Clusters \\
\hline 9 & 10 \\
8 & 44 \\
7 & 58 \\
6 & 86 \\
5 & 125 \\
4 & 226 \\
3 & 453 \\
2 & 1,073 \\
1 & 974 \\
\hline
\end{tabular}

proteins involved in plant cell wall degradation, whereas the PMK1 mutant (mk) library had the next highest representation of these enzymes with just 17 ESTs $(0.38 \%)$.

\section{Gene expression.}

The 24 most abundantly represented genes across all libraries are shown in Table 6. As expected, a number of housekeeping genes involved in protein translation, carbon metabolism, and energy production were identified, and these were represented in all or most of the libraries. The most abundantly represented gene was the $M$. grisea homolog of the UVI-1 appressorium and UV-inducible gene of Bipolaris oryzae (Kihara et al. 2001), with 622 ESTs. This represented $2.2 \%$ of all sequences and $12 \%$ of mating $(\mathrm{mt})$ library sequences. In addition, a homolog of the $N$. crassa ccg- 1 (clock-controlled gene), a small protein of unknown function (McNally and Free 1988), was represented fairly evenly across all libraries. The $N$. crassa and Fusarium graminearum homologs of this gene are highly represented in their respective EST datasets (Nelson et al. 1997; Trail et al. 2003).

We used EST abundance as a measure of expression level, and hierarchical clustering was used to group these genes according to expression patterns (Fig. 1). The hierarchical clustering was limited to 207 significantly differentially expressed EST clusters, as determined by the likelihood ratio technique of Stekel and associates (2000). The UVI-1 homolog was most abundant in the mt, ap, cs, and mk libraries, reflecting an association with developmental processes (perithecia, appressoria, and conidia). The function of UVI-1 in these processes is unknown; however, genes with a similar expression pattern include a homolog of a protein that interacts with adenylate cy-

Table 5. Gene ontology (GO) functional assignments

\begin{tabular}{|c|c|c|c|c|c|c|c|c|c|c|}
\hline GO term & GO \# & $\mathbf{a p}^{\mathbf{a}}$ & cw & cs & cm & mt & my & mk & ns & su \\
\hline Cellular component & GO:0005575 & 22.20 & 22.20 & 34.10 & 23.52 & 23.25 & 26.37 & 28.57 & 26.10 & 27.25 \\
\hline Extracellular & GO:0005576 & 0.49 & 0.94 & 0.21 & 0.13 & 0.28 & 0.07 & 0.41 & 0.05 & 0.29 \\
\hline Cell & GO:0005623 & 20.49 & 19.27 & 33.01 & 22.58 & 22.30 & 25.96 & 27.69 & 24.59 & 25.99 \\
\hline Cell wall & GO:0005618 & 1.22 & 2.91 & 1.00 & 0.60 & 5.57 & 0.48 & 0.36 & 0.30 & 0.19 \\
\hline Unlocalized & GO:0005941 & 0.49 & 0.03 & 0.12 & 0.03 & 0.12 & 0.00 & 0.07 & 0.14 & 0.10 \\
\hline Cellular component unknown & GO:0008372 & 1.22 & 2.50 & 0.85 & 0.81 & 0.64 & 0.41 & 0.75 & 1.35 & 0.97 \\
\hline Biological process & GO:0008150 & 43.17 & 29.70 & 48.55 & 37.02 & 36.57 & 41.60 & 41.62 & 40.49 & 39.23 \\
\hline Metabolism & GO:0008152 & 30.49 & 23.17 & 37.42 & 32.41 & 20.50 & 32.45 & 34.99 & 35.64 & 33.04 \\
\hline Gluconeogenesis & GO:0006094 & 0.24 & 0.23 & 0.03 & 0.16 & 0.12 & 0.55 & 0.20 & 0.56 & 0.10 \\
\hline Transport & GO:0006810 & 5.37 & 7.49 & 14.07 & 10.71 & 5.69 & 6.01 & 7.46 & 7.75 & 5.80 \\
\hline Death & GO:0016265 & 0.00 & 0.08 & 0.03 & 0.00 & 0.05 & 0.07 & 0.07 & 0.19 & 0.00 \\
\hline Response to stress & GO:0006950 & 2.44 & 2.85 & 1.20 & 2.25 & 0.83 & 0.61 & 1.27 & 1.37 & 1.26 \\
\hline Cell cycle & GO:0007049 & 2.44 & 0.23 & 2.76 & 1.25 & 1.18 & 1.64 & 2.01 & 1.83 & 2.13 \\
\hline Cell communication & GO:0007154 & 3.41 & 0.84 & 3.52 & 1.79 & 1.63 & 1.84 & 1.95 & 2.11 & 1.16 \\
\hline Development & GO:0007275 & 0.98 & 0.25 & 1.47 & 1.88 & 0.64 & 0.89 & 0.93 & 1.04 & 1.35 \\
\hline Physiological processes & GO:0007582 & 36.59 & 29.42 & 47.93 & 36.14 & 25.06 & 37.57 & 40.94 & 39.95 & 37.97 \\
\hline Carbohydrate metabolism & GO:0005975 & 3.17 & 6.19 & 2.73 & 2.98 & 1.67 & 2.94 & 1.92 & 3.18 & 3.48 \\
\hline Biological process unknown & GO:0000004 & 1.95 & 1.15 & 0.70 & 0.75 & 0.46 & 0.55 & 0.57 & 0.70 & 0.97 \\
\hline Molecular function & GO:0003674 & 38.29 & 33.16 & 51.07 & 41.90 & 33.42 & 38.05 & 42.91 & 40.37 & 38.65 \\
\hline Binding activity & GO:0005488 & 18.05 & 10.63 & 28.99 & 16.60 & 14.35 & 17.90 & 22.10 & 19.79 & 18.45 \\
\hline Nucleic acid binding activity & GO:0003676 & 8.05 & 3.36 & 10.69 & 5.20 & 5.98 & 7.58 & 10.00 & 9.30 & 6.67 \\
\hline Carbohydrate binding activity & GO:0030246 & 0.98 & 0.99 & 1.82 & 0.25 & 0.31 & 0.75 & 0.88 & 0.14 & 0.48 \\
\hline Transcription regulator activity & GO:0030528 & 0.00 & 0.15 & 0.26 & 0.13 & 0.46 & 0.34 & 0.48 & 0.32 & 0.39 \\
\hline Chaperone & GO:0003754 & 0.00 & 0.05 & 0.21 & 0.06 & 0.21 & 0.14 & 0.27 & 0.14 & 0.39 \\
\hline Enzyme activity & GO:0003824 & 18.54 & 18.51 & 23.41 & 24.12 & 10.98 & 15.03 & 17.98 & 19.86 & 19.42 \\
\hline Hydrolase activity & GO:0016787 & 8.78 & 7.44 & 9.69 & 8.46 & 4.45 & 5.26 & 6.65 & 7.12 & 5.89 \\
\hline Enzyme regulator & GO:0030234 & 0.24 & 0.10 & 0.26 & 0.03 & 0.23 & 0.20 & 0.16 & 0.16 & 0.29 \\
\hline Structural molecule activity & GO:0005198 & 3.90 & 2.80 & 8.87 & 5.92 & 9.42 & 8.88 & 8.60 & 7.08 & 5.31 \\
\hline Transporter & GO:0005215 & 8.29 & 7.19 & 15.01 & 12.18 & 6.64 & 8.61 & 9.09 & 8.63 & 8.12 \\
\hline Electron transporter activity & GO:0005489 & 5.12 & 3.19 & 3.64 & 2.69 & 2.45 & 3.35 & 3.87 & 2.90 & 3.00 \\
\hline Ion transporter activity & GO:0015075 & 1.71 & 1.20 & 5.43 & 2.22 & 1.72 & 2.60 & 2.71 & 2.34 & 2.80 \\
\hline Carbohydrate transporter activity & GO:0015144 & 0.73 & 0.41 & 1.06 & 0.28 & 0.32 & 0.14 & 0.66 & 0.23 & 0.19 \\
\hline Signal transducer & GO:0004871 & 1.22 & 1.22 & 1.62 & 0.78 & 1.23 & 1.30 & 1.31 & 1.14 & 1.74 \\
\hline Molecular function unknown & GO:0005554 & 1.95 & 4.33 & 1.73 & 1.35 & 1.53 & 1.09 & 1.22 & 1.97 & 1.45 \\
\hline
\end{tabular}

${ }^{\mathrm{a}}$ Library abbreviations: ap = appressorium, $\mathrm{cm}=$ complete medium, $\mathrm{cs}=$ conidiospore, $\mathrm{cw}=$ rice cell wall, $\mathrm{mk}=\mathrm{PMK} 1 \mathrm{mutant}, \mathrm{mt}=\mathrm{mating}, \mathrm{my}=\mathrm{mycelial}$, $\mathrm{ns}=$ nitrogen starvation, and $\mathrm{su}=$ subtracted. 
clase (Kulkarni and Dean 2004) and a gene with similarity to delta-24-sterol methyltransferase. cAMP signaling plays a key role in the induction of appressorium formation, and the adenylate cyclase interacting protein, therefore, may play an important role in these developmental processes. The UVI-1 homolog, adenylate cyclase-interacting protein, and the sterol methyltransferase were also detected in the mk library, suggesting that their expression was not dependent on the PMK1 MAP kinase.

The MPGl gene encodes a fungal hydrophobin that decorates the surface of the cell wall of the fungus (Kershaw et al. 1998). MPG1 was abundantly expressed (563 ESTs) and was most prevalent in the $\mathrm{mt}, \mathrm{cw}$, and cs libraries but was found in all libraries (Fig. 1). Expression of MPG1 was observed in both the ap and mk libraries, suggesting that, like UVI-1, $M P G 1$ regulation during germination and appressorium development is not dependent on PMKl.

As was observed for UVI-1, ESTs corresponding to the $M A S 1 / G A S 2$ (c19) and MAS3/GAS1 (cl1353) virulence factors (Xue et al. 2002) were abundant in the ap library (Fig. 1). However, they were absent from the mk library, suggesting $P M K 1$-dependent expression of these genes. This finding indicates that a more comprehensive comparison of transcriptional profiles to identify $P M K 1$-dependent genes will be useful in identification of new virulence factors that participate early in the infection process.

The 325 ESTs in cl2363 represent a gene that has weak similarity to putative protein methyltransferases. The polypeptide predicted from the cl2363 coding region contains a highly conserved motif found in the SET domain (Zhang et al. 2003). SET domains have been shown to be important for proteinprotein interactions as well as protein-lysine methyltransferase activity that methylates histones. The cl2363 gene is expressed predominantly during nitrogen starvation.
Clusters cl2052 and cl2665 (Table 6, Fig. 1) have homology to reverse transcriptases and were physically associated with repeat elements MGL/MGR583 (AF018033) (Dioh et al. 2000). The occurrence of these ESTs varies across the libraries. A low frequency of ESTs was observed for the cw, mk, and mt libraries $(0.15,0.30$, and $0.38 \%$, respectively), and a higher frequency was observed for the $\mathrm{cm}, \mathrm{ns}$, cs, and mycelial (my) libraries $(0.94,1.1,1.2$ and $5.0 \%$, respectively). The oligo-dT primers used to generate the libraries should enrich for polyadenylated transcripts, and several EST sequences revealed polyA tails on transcripts, suggesting that polyadenylated transcripts are produced from these sequences. However, because of their repetitive nature, clusters were produced that may represent multiple loci. Thus, predicting whether the transcripts would give rise to functional proteins was not possible.

\section{ESTs reveal a family of small fungal metallothioneins.}

Four members of a metallothionein gene family similar to a metallothionein from $N$. crassa (Munger et al. 1985) were detected in the EST sequences, and we did not detect any additional family members in the $M$. grisea genome sequence. Two abundantly expressed genes, represented by cl1497 (471 ESTs) and cl2379 (335 ESTs), encode members of this family that we named CMT1 (copper metallothionein) and CMT2, respectively. CMT2 appears to be the ortholog of the characterized metallothionein of $N$. crassa. The 10th most abundant transcript represented by c1692 (182 ESTs, CMT3) and another gene represented by cl1676 (20 ESTs, CMT4) (18 ESTs from the mt library, two from the cs library) also encode members of this family. The coding regions of the genes are predicted to produce polypeptides of 22 to 28 amino acids (aa). Analysis of EST data from $N$. crassa and $F$. graminearum demonstrates that this gene family is conserved among these

Table 6. The most abundantly represented genes

\begin{tabular}{|c|c|c|c|}
\hline Cluster ID & Clones $^{\mathbf{a}}$ & Annotation $^{b}$ & Libraries $^{c}$ \\
\hline $\operatorname{cl} 652$ & 622 & UVI-1, MG02647.4 & ap, cs, mk, mt, ns, su \\
\hline $\operatorname{cl} 2104$ & 563 & MPG1, MG10315.4 & $\mathrm{ap}, \mathrm{cm}, \mathrm{cs}, \mathrm{cw}, \mathrm{mk}, \mathrm{mt}, \mathrm{ns}, \mathrm{su}$ \\
\hline $\mathrm{cl1497}$ & 471 & $\mathrm{CMT} 1^{\mathrm{d}}$ & $\mathrm{cm}, \mathrm{cs}, \mathrm{cw}, \mathrm{mt}, \mathrm{my}, \mathrm{ns}$ \\
\hline $\operatorname{cl} 2379$ & 335 & $\mathrm{CMT} 2^{\mathrm{d}}$ & $\mathrm{cs}, \mathrm{cw}, \mathrm{mk}, \mathrm{mt}, \mathrm{my}, \mathrm{ns}$ \\
\hline $\operatorname{cl} 2363$ & 325 & $\begin{array}{l}\text { Unknown 213-aa weak homology protein lysine methyltransferase (SET } \\
\text { domain) MG00019.4 }\end{array}$ & $\mathrm{cm}, \mathrm{mt}, \mathrm{ns}$ \\
\hline cl1197 & 325 & Formate dehydrogenase, MG04034.4 & ap, cm, cs, cw, mk, mt, my \\
\hline $\operatorname{cl} 2665$ & 232 & $\begin{array}{l}\text { Reverse transcriptase, found in multiple ORFs predicted by automated } \\
\text { annotation }\end{array}$ & $\mathrm{cm}, \mathrm{cs}, \mathrm{cw}, \mathrm{mk}, \mathrm{mt}, \mathrm{my}, \mathrm{ns}$ \\
\hline cl123 & 190 & Ketoreductase (nor1), MG10274.4 & $\mathrm{cm}, \mathrm{cs}, \mathrm{ns}, \mathrm{su}$ \\
\hline cl1955 & 184 & Translation elongation factor 1 alpha, MG03641.4 & ap, cm, cs, cw, mk, mt, my, ns \\
\hline $\operatorname{cl} 692$ & 182 & $\mathrm{CMT}^{\mathrm{d}}$ & $\mathrm{cm}, \mathrm{cs}, \mathrm{cw}, \mathrm{mk}, \mathrm{mt}, \mathrm{my}, \mathrm{ns}$ \\
\hline cl434 & 178 & Unknown: encodes 89-aa ORF; MG09549.4 ${ }^{\mathrm{d}}$ & $\mathrm{cm}, \mathrm{cs}, \mathrm{cw}, \mathrm{my}, \mathrm{su}$ \\
\hline cl1314 & 153 & ADP-ATP translocase, MG06656.4 & $\mathrm{cm}, \mathrm{cs}, \mathrm{cw}, \mathrm{mk}, \mathrm{mt}, \mathrm{my}, \mathrm{ns}, \mathrm{su}$ \\
\hline $\mathrm{cl} 34$ & 144 & Unknown 347-aa weak homology to methyltransferases, MG02966.4 & $\mathrm{cm}, \mathrm{mk}, \mathrm{ns}$ \\
\hline $\mathrm{cl} 2413$ & 144 & 40S ribosomal protein S5, MG06658.4 & ap, cs, cw, mk, mt, my, ns \\
\hline $\operatorname{cl} 2240$ & 129 & $\mathrm{H}+$ transporting two-sector ATPase, MG04479.4 & $\mathrm{ap}, \mathrm{cm}, \mathrm{cs}, \mathrm{cw}, \mathrm{mk}, \mathrm{mt}, \mathrm{my}, \mathrm{ns}$ \\
\hline $\mathrm{cl} 2594$ & 120 & Unknown 229 aa, no homology in Neurospora crassa, MG07975.4 & $\mathrm{cm}, \mathrm{cs}, \mathrm{cw}, \mathrm{mk}, \mathrm{mt}, \mathrm{my}, \mathrm{ns}, \mathrm{su}$ \\
\hline $\operatorname{cl} 2427$ & 118 & Short chain alcohol dehydrogenase, MG02612.4 & $\mathrm{cm}, \mathrm{cs}, \mathrm{cw}, \mathrm{mk}, \mathrm{ns}, \mathrm{su}$ \\
\hline $\operatorname{cl} 2552$ & 116 & $\begin{array}{l}\text { Unknown 95-aa; Ser-rich N-terminus; } 7 \text { cys residues in C-terminal } 28 \text { aa; } \\
\text { ProtComp prediction extracellular/nuclear; no homology in N. crassa, } \\
\text { MG09761.4 }\end{array}$ & $\mathrm{cm}, \mathrm{cs}, \mathrm{cw}, \mathrm{mk}, \mathrm{mt}, \mathrm{my}, \mathrm{ns}, \mathrm{su}$ \\
\hline $\mathrm{cl} 2014$ & 104 & Glyceraldehyde 3-phosphate dehydrogenase, MG01084.4 & $\mathrm{cm}, \mathrm{cs}, \mathrm{cw}, \mathrm{mk}, \mathrm{mt}, \mathrm{my}, \mathrm{ns}, \mathrm{su}$ \\
\hline $\mathrm{cl} 82$ & 103 & Unknown; 71-aa ORF; MG00715.4 & ap, cm, cs, cw, mk, mt, my, ns \\
\hline cl1603 & 103 & Trihydroxynaphthalene reductase, bufl, MG02252.4 & $\mathrm{ap}, \mathrm{cm}, \mathrm{cs}, \mathrm{cw}, \mathrm{mk}, \mathrm{mt}, \mathrm{ns}, \mathrm{su}$ \\
\hline $\mathrm{cl} 2287$ & 96 & Histone H4, MG06293.4, and MG01160.4 & $\mathrm{cm}, \mathrm{cs}, \mathrm{cw}, \mathrm{mk}, \mathrm{mt}, \mathrm{my}, \mathrm{ns}, \mathrm{su}$ \\
\hline $\operatorname{cl} 528$ & 93 & Flavohemoglobin, MG00198.4 & $\mathrm{cw}, \mathrm{mk}$ \\
\hline $\mathrm{cl} 723$ & 90 & Coproporphyrinogen oxidase precursor, MG01061.4 & $\mathrm{cm}, \mathrm{cs}, \mathrm{cw}, \mathrm{mk}, \mathrm{my}, \mathrm{ns}$ \\
\hline
\end{tabular}

\footnotetext{
a Number of expressed sequence tags (ESTs) in cluster.

${ }^{\mathrm{b}}$ Best blast hit $\left(\max \mathrm{e}^{-5}\right)$.

${ }^{\mathrm{c}}$ Libraries containing ESTs of the cluster. Library abbreviations: $\mathrm{ap}=$ appressorium, $\mathrm{cm}=\mathrm{complete}$ medium, $\mathrm{cs}=\mathrm{conidiospore}, \mathrm{cw}=$ rice cell $\mathrm{wall}, \mathrm{mk}=$ PMK1 mutant, $\mathrm{mt}=$ mating, $\mathrm{my}=$ mycelial, $\mathrm{ns}=$ nitrogen starvation, and su = subtracted.

${ }^{\mathrm{d}}$ Open reading frame (ORF) not predicted by automated annotation or inconsistent with EST sequence.
} 

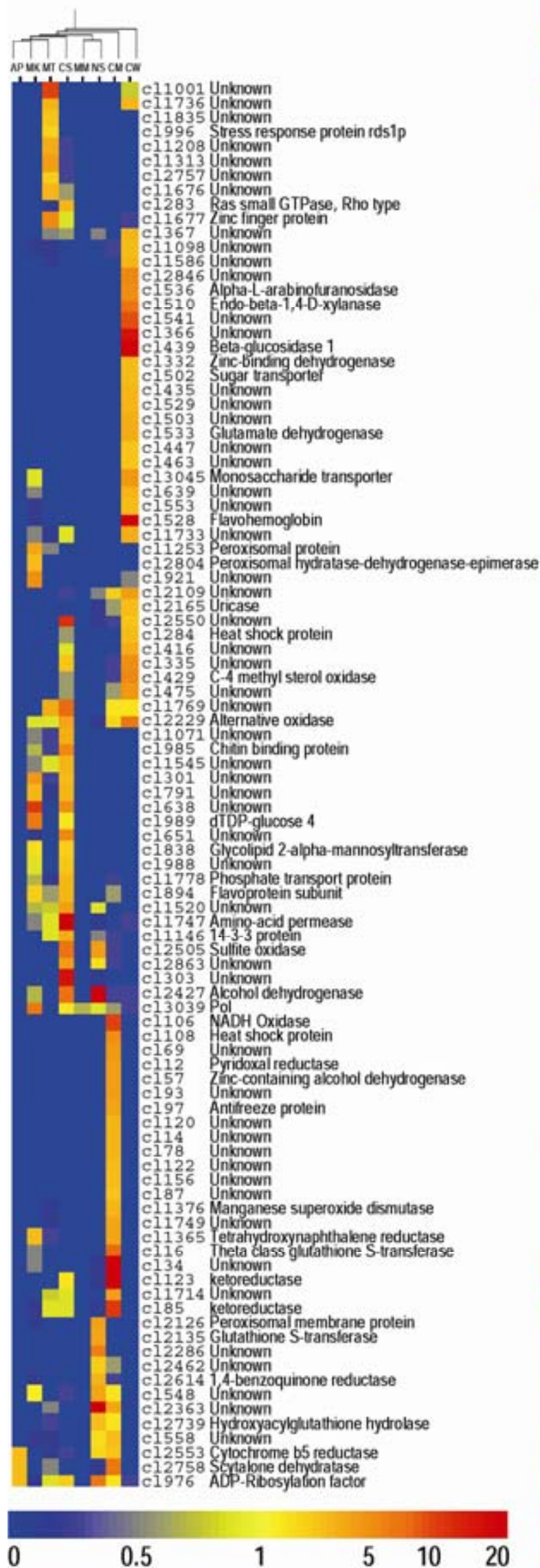

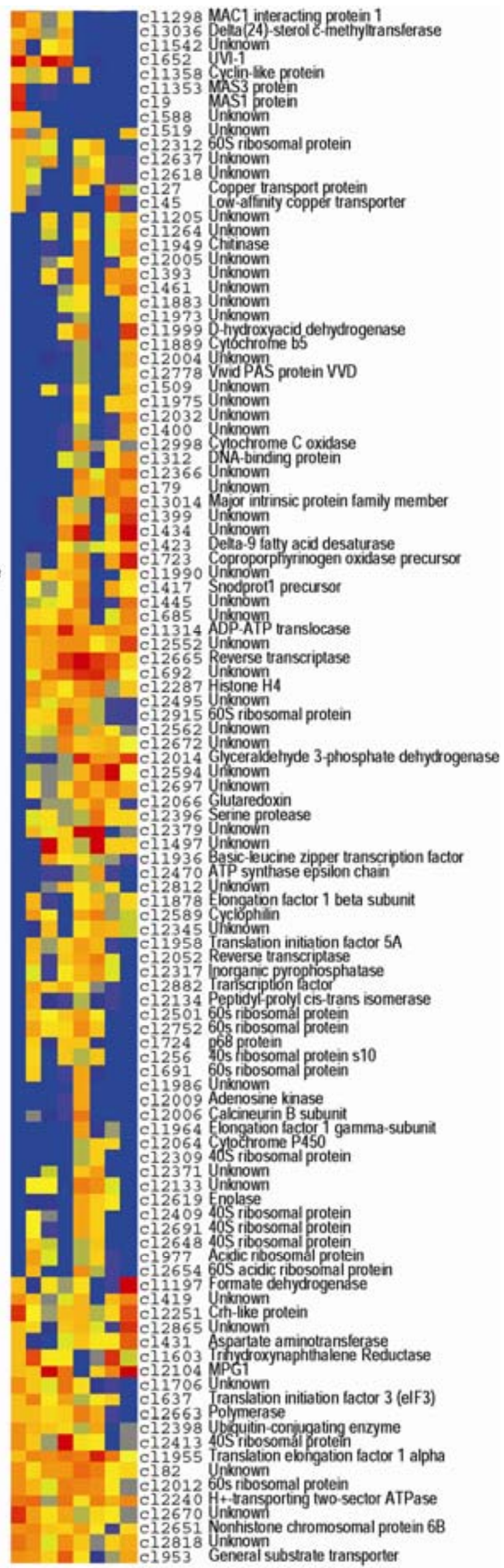

Fig. 1. Clustering of gene expression based on expressed sequence tag abundance. AP, appressorium library; MK, PMK1 mutant library; MT, mating library; CS, conidiospore library; MM, mycelial library; NS, nitrogen starvation library; CM, complete medium library; and CW, rice cell wall library. Relative abundance in parts per thousand is indicated by scale bar. 
fungi and is highly expressed (Fig. 2). These genes are most abundantly represented in the ns library in $M$. grisea but differ in their gene expression patterns (Fig. 1).

\section{Library-specific gene expression.}

As mentioned above, we performed EST hierarchical clustering analysis to identify patterns of gene expression for 207 differentially expressed genes. This analysis found clusters of genes that were specific to each library and to combinations of libraries (Fig. 1). The abundant unique genes associated with each library provide candidate genes that might contribute to developmental processes or adaptation to different growth conditions. For example, an abundantly expressed gene in the $\mathrm{mt}$ library (Fig. 1, cl1001, top line, left column) was the MAT1-1 pheromone precursor gene (Shen et al. 1999).

Genes found uniquely in the ap library were also detected (MAS1, MAS3), as were genes that were expressed predominantly in the ap library but were also expressed in one or more of the other libraries (Fig. 1, cl1298 to cl1598, top of the second column). Other genes that were significantly expressed in the ap library but not present in the mk library were a homolog of a low affinity copper transporter and a gene with no homolog of known function. Thus, these genes are candidates for being PMK1-regulated or appressorium-specific.

Genes exclusively or predominantly found in the cw library include a wide variety of plant cell wall-degrading enzymes, such as arabinofunanosidases, xylanases, and cellulases, as well as sugar transporter homologs. In addition, genes encoding a flavohemoglobin, coporphyrinogen oxidase, and formate dehydrogenase were highly represented in the cw library. These genes likely play a role in adapting to growth on cellulose and hemicellulose substrates. No ESTs with homology to polygalacturonases were identified, except for a single EST representing a pectin methylesterase, suggesting that little or no pectic substrates remained in the cultures at the time of harvest. Several ESTs with no homology to sequences in the databases were specifically expressed in the cw library.

As an alternate approach, we also examined the representation of genes for specific pathways known to be important for plant infection. For example, melanin formation in appressoria is criti-

$$
\begin{aligned}
& \text { Stackpack } \\
& \text { cluster ID } \\
& \text { mgcl } 692 \\
& \text { nccl193 } \\
& \text { fgcl175 } \\
& \text { fgUORF1 } \\
& \text { fgUORF2 } \\
& \text { nccl } 861 \\
& \text { mgcl2379 } \\
& \text { fgcl } 487 \\
& \text { mgcl1676 } \\
& \text { mgcl1497 }
\end{aligned}
$$$$
\text { putative coding region }
$$$$
\text { Number }
$$$$
\text { of ESTs }
$$

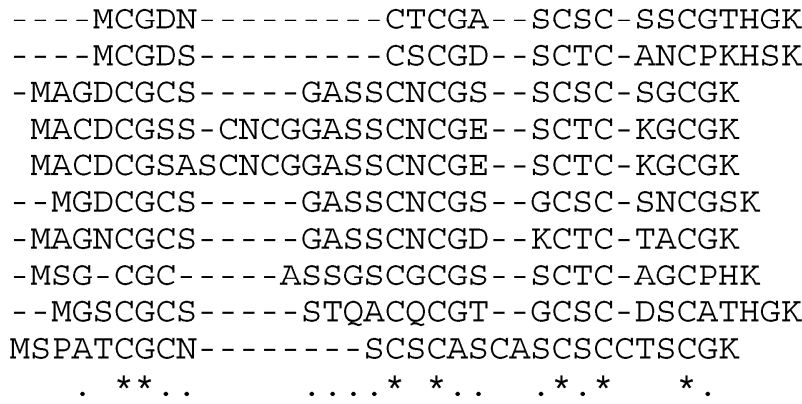

$\begin{array}{rrr}22 & 180 & \text { (СMT3) } \\ 22 & 69 & \\ 26 & 47 & \\ 30 & 0 & \\ 31 & 0 & \\ 26 & 335 & \text { NC } \mathrm{MT} \\ 26 & 334 & \text { (CMT2) } \\ 26 & 2 & \\ 28 & 20 & \text { (CMT4) } \\ 27 & 465 & \text { (CMT1) }\end{array}$

Fig. 2. Identification of a family of metallothioneins encoded by abundantly expressed genes. Expressed sequence tag (EST) clusters from StackPack analysis were identified by tblastn analysis of the Magnaporthe griesa CMT proteins. Open reading frames (ORF) from Neurospora crassa EST and Fusarium graminearum EST and genomic sequences were conceptually translated and aligned by hand with the $M$. grisea sequence. Alignments were edited by hand to preserve the position of six cysteine residues. Asterisks $(*)$ indicate identical residues in all polypeptides; periods (.) indicate conserved amino acid. The Stackpack cluster ID, Broad Institute ORF ID, putative coding region, the number of residues for each polypeptide, and the number of ESTs for each cluster are indicated.

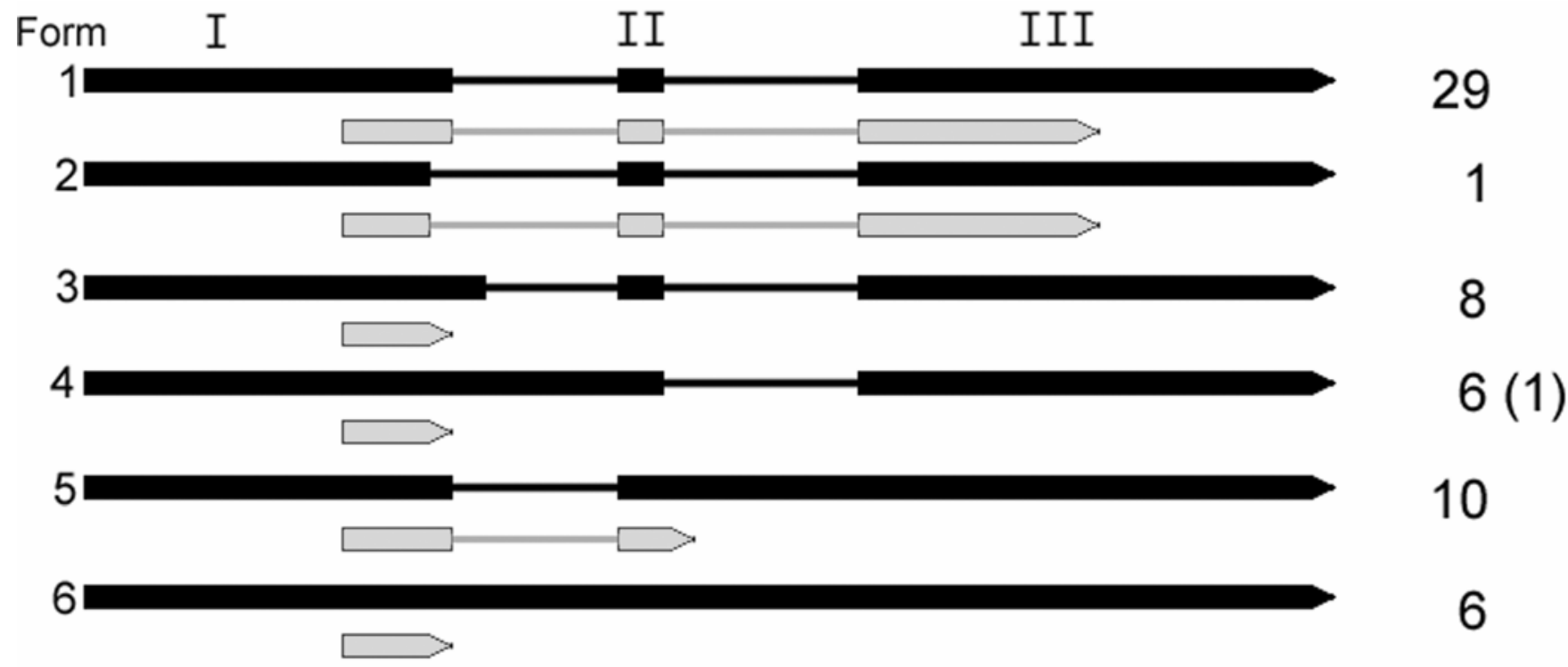

Fig. 3. Schematic representation of alternative splicing of transcripts corresponding to the coding region for MG05058.4. mRNA forms 1 through 6 represent distinct transcript species (shown in black). Exons are represented by boxed regions (labeled I, II, and III for form 1). Introns are represented by thin lines. The regions predicted to be translated into polypeptides are indicated in gray beneath the corresponding mRNA species. 
cal for appressorial penetration of the host. ESTs representing trihydroxynaphthalene reductase, tetrahydroxynaphthalene reductase, and scytalone dehydratase were present in the ap or the mk libraries, or both, consistent with the production of melanin pigment in germlings destined to form appressoria. The genes were also highly expressed in the cm library. Both tetrahydroxynaphthalene reductase and scytalone dehydratase cluster near one another (Fig. 1). Trihydroxynaphthalene reductase is found elsewhere in the analysis, due to its broader representation among the libraries; however, these three genes are among the 30 most abundantly represented ESTs in the cm library.

\section{Alternative transcript forms.}

EST sequences may be present in alternate forms, either due to differences in transcription initiation or termination sites or as alternatively spliced forms. Analysis by StackPack 2.1 suggests there are 134 genes with alternate expression forms that may represent alternative splicing. In the majority of cases the different forms represented transcripts with one or more introns spliced in one form and unspliced in the other form. Comparison of EST transcript forms to the $M$. grisea genome sequence allowed us to carefully examine a number of these alternate forms, and the results of this analysis for one of these genes is illustrated in Figure 3. The gene, represented by 66 EST clones, encodes a hypothetical protein conserved in $N$. crassa (NCU05338.1). In $N$. crassa, this gene is represented by 314 EST sequences. The $N$. crassa gene also contains two introns; however, no splicing variants were found. In our libraries, 51 of the 66 ESTs representing the gene were from the cw library. The predominant form was represented by 29 ESTs that provided evidence for splicing of two introns (Fig. 3, form 1). Form 2 possessed an aberrant $5^{\prime}$ splice site for the first intron that was $21 \mathrm{nt}$ upstream of the splice site for form 1 RNA. The consensus sequence for intron 5 ' splice junctions in the filamentous ascomycete fungi examined to date is $5^{\prime}$ GTRNGT-3' ( $\mathrm{R}=$ purine; $\mathrm{N}=$ any nucleotide), with the $5^{\prime}-\mathrm{GT}$ being invariant (Edelmann and Staben 1994). The 5' splice site for form 2 was 5'-GCATGT-3'. The use of this site for splicing could result from a rare event, such as base misincorporation during transcription, spontaneous deamination of $\mathrm{C}$ to $\mathrm{U}$ in the RNA prior to splicing, or an error in the splicing process. Form 3 RNA was represented by eight EST sequences and represents splicing at a second $5^{\prime}$ splice site $32 \mathrm{nt}$ downstream of that used for form 1 RNA. Increasing the length of exon I leads to premature termination of the coding region. Forms 4, 5, and 6 represented RNA species that fail to splice the first, the second, or both introns, respectively. In the case of form 4 , five of the six EST sequences do not reach the second intron, and we cannot determine if these five should be catalogued as form 4 or form 6.

Form 1 is predicted to encode the functional polypeptide because of sequence conservation with the $N$. crassa polypeptide. However, approximately half of the total number of ESTs that can be classified into a form category are predicted to produce a truncated polypeptide, presumably indicating that primary transcripts from this gene are frequently misspliced. The form of all 314 examples of ESTs from $N$. crassa for the homologous gene was consistent with being equivalent to form 1 RNA. Thus, one possibility is that $N$. crassa is much more efficient than $M$. grisea at correctly splicing the analogous RNA species. However, we cannot exclude the possibility that there is tissue- or growth condition-specific control of splice form. In the cw library, there were 21 form 1 ESTs and 23 ESTs of the other forms. For the cs library, six ESTs were form 1 and one EST was form 4, whereas for the cm library, none of the three ESTs were of form 1 RNA.

\section{DISCUSSION}

ESTs complement the value of genomic sequence by functional identification of genes, providing information on gene structure and information about gene expression patterns. The majority of the 8,177 clusters and singletons identified in our analysis represent unique genes, and we estimate that more than half of the gene content of $M$. grisea is represented in this collection of sequences. We found that 4,677 of the 8,177 $(57 \%)$ unique sequences have matches in the $N$. crassa genome, based on tblastx $\left(<\mathrm{e}^{-5}\right)$.

A strategy of sequencing a variety of different libraries was used to maximize the number of unique genes. This strategy appears to have been successful, as indicated by the differential representation of ESTs across libraries and the high frequency of library-specific unique genes. A comparison of the ESTs with the $M$. grisea genome sequence revealed that $95 \%$ of the sequences align to the genome at a blastn match (using e value $=\mathrm{e}^{-30}$ ). The ESTs that do not have sequence matches in the genome likely represent gaps in the genome sequence but may also represent genes that are unique to the different strains used to produce the cDNA libraries. The frequency of sequences that do not match the genome is similar between libraries, supporting the view that these are predominantly genes that fall within sequencing gaps. The use of different strains for library construction also permits the identification of single nucleotide polymorphisms (SNP). Manual annotation of a subset of clusters revealed that SNP are present at a low level, based on multiple occurrences of ESTs representing variants; however, additional systematic analysis of SNP occurrence remains to be performed.

A hierarchical clustering approach was used to assess EST abundance and to visualize expression patterns within the RNA used for library construction. Genes expressed during appressorium formation fell into two major clusters, one being more appressorium-specific (Fig. 1, starting at the bottom left column with the cl2553 cytochrome b5 reductase homolog and continuing at the top of the right column to the cl45 low-affinity copper transporter homolog). The second group of genes was expressed abundantly across most libraries (Fig. 1, bottom right column starting with formate dehydrogenase). Expression patterns could be discerned for a number of genes that are consistent with previously determined expression patterns. For example, the expression of genes such as UVI-1, MPG1, MAS1, MAS3, MAC1-interacting protein, and genes for melanin synthesis was found to be expressed during appressorium formation, consistent with previous studies. MAS1 and MAS3 are known virulence determinants that were expressed in the ap library but were not expressed in the mk or any other library. Other genes expressed at a higher level in wild-type than in pmk1 germlings are scytalone dehydrogenase (melanin synthesis), cytochrome b5 reductase, ADP-ribosylation factor, aspartate aminotransferase, formate dehydrogenase, low affinity copper transport protein, and a protein of unknown function. However, these latter proteins all have significant levels of expression in other libraries, and none of those with assigned functions are thought to play a direct role in interacting with the host. Therefore, differential expression between PMK1/pmkl strains during germination coupled with the absence of expression in a variety of other growth conditions represents an expression pattern that can be used as a criterion to identify candidate virulence genes. Whole genome microarrays comparing these strains will likely identify a significant number of new candidate genes.

Genes in the mk library are expressed in the absence of a functional $P M K 1$ gene. The genes represented in the mk library are not likely to be critical in appressorium development but 
may be important for germination of conidia. In this regard, it is noteworthy that there were a number of genes expressed in common between the mk and cs library. $M$. grisea conidia germinate very quickly, and possibly, the harvested conidia were becoming activated and beginning early stages of germination prior to RNA extraction. The finding of large numbers of ESTs representing ribosomal proteins and translation initiation factors is consistent with this view.

The mt ESTs fell into three major clusters. The first group of ESTs was mostly present only in the mt library. The MAT1-1 strain served as the female parent in the cross used to produce the mt library and so provided most of the RNA for library construction. This likely explains why the MAT1-1 pheromone precursor gene was abundant but no cDNA clones for the MAT1-2 pheromone precursor gene was detected in the EST data. The second group of mt ESTs clustered with genes from the ap, mk, and cs libraries. These may be development-specific genes. The third group of mt ESTs represented genes expressed in several other libraries.

The my and cw libraries displayed similar patterns of gene expression, except for the large cluster of cw-specific genes that appear to be involved in cell wall degradation. Although only a few cell wall-degrading enzymes were expressed at high enough levels for inclusion in Figure 1, a wide variety of enzymes for plant cell wall degradation were expressed in the cw library.

There were relatively few ns-induced transcripts that were not also represented in other libraries. In contrast, the $\mathrm{cm}$ library showed a cluster of largely complete medium-specific expression. Unfortunately, many of these genes do not code for proteins of known function, although the occurrence of NADH oxidase, superoxide dismutase, and theta-glutathione-S-transferase suggest oxidative stress may be a factor influencing expression of this cluster of genes.

A previous analysis of ESTs from $M$. grisea-infected rice plants identified 72 fungal genes expressed during infection (Kim et al. 2001). Among the four genes classified as being involved in cell or organism defense and pathogenesis, three were represented in our EST collection: cl2104 (MPG1, 563 ESTs), cl82 (N. crassa grg-1 homolog, 103 ESTs), and cl1214 (N. crassa bli-7 homolog, two ESTs). A hydrophobin (protein ID MG01174.4) was expressed in planta but was not represented in the EST dataset.

SAGE analysis comparing cAMP-treated with control $M$. grisea germlings identified putative cAMP-regulated genes (Irie et al. 2003). Several of these genes including MPG1, transcripts with homology to reverse transcriptase (c12665), an ADP-ATP translocase (cl1314), the $N$. crassa grg- 1 homolog (c182), and trihydroxynaphthalene reductase (buf1) are among the most abundantly represented genes in our EST dataset (Table 6).

\section{Gene discovery.}

Genes encoding small polypeptides pose problems for genomic analysis. They would be difficult to predict with confidence directly from genomic sequence, and their small size might hinder their identification through biochemical approaches. The isoprenylated pheromone precursor gene (cl1001, MG02452.4) found abundantly in the mt library is an example of a coding region specifying an open reading frame (ORF) of only 26 aa (Shen et al. 1999).

Other small, highly expressed genes of filamentous fungi have been shown to play critical roles as morphogenetic factors. For example, hydrophobins are small (approximately $100 \mathrm{aa}$ ), often highly expressed polypeptides with eight cysteines arranged in a characteristic pattern. The MPGl hydrophobin plays a critical role in controlling the surface characteristics of fungal hyphae and also plays a role in surface interactions that are needed to promote appressorium formation on the host surface (Beckerman and Ebbole 1996; Kershaw et al. 1998; Talbot et al. 1993, 1996). In Schizophyllum commune, hydrophobins not only function as morphogenetic determinants of aerial growth for submerged hyphae, they also are important for fruiting body development (Lugones et al. 1999; Wosten et al. 1999). The finding that $M P G 1$ was most highly represented in the mt library likely reflects the abundance of aerial tissue but also raises the possibility of a role for hydrophobins in fruiting body formation in ascomycete fungi. In addition to $M P G 1$, we detected ESTs representing three additional hydrophobin proteins. These include cl531 (three ESTs) corresponding to MG09134.4, cl500 (four ESTs) corresponding to MG04354.4, and $\mathrm{mt} 013 \mathrm{xH} 23$ corresponding to MG07411.4. No ESTs were found corresponding to magnaporin, a known hydrophobin of M. grisea (GenBank accession number AF126872). Two additional apparent hydrophobin proteins were found in the genome sequence of $M$. grisea, MG10105.4, and MG04355.4 (adjacent to the MG4354.4 hydrophobin identified by the mgmt013xH23 EST). Thus, four of the seven likely hydrophobin genes of $M$. grisea were identified by EST analysis. Because of the importance of the MPGl hydrophobin gene in virulence, it will be of interest to functionally assess the contribution of the expressed hydrophobins to virulence.

Manual annotation of highly expressed genes allowed us to identify a family of short (22 to 28 aa) serine/threonine and cysteine-rich ORFs encoding metallothioneins. Two family members were detected in $N$. crassa ESTs and in the genome sequence. The gene for one of these metallothioneins has previously been characterized in $N$. crassa (Munger et al. 1985). In F. graminearum, two members were also represented in the ESTs; however, two additional family members could be detected in the genome sequence. Interestingly, the two additional family members are highly related to each other (92\% identical at the DNA sequence level), suggesting that this pair has recently arisen by gene duplication. The number of family members also appears to be expanded in the plant pathogens (four) relative to $N$. crassa (two), suggesting that they may be specialized for a role in plant interactions. The cap3 metallothionein of Colletotrichum gloeosporioides (Hwang and Kolattukudy 1995) is expressed specifically during appressorium formation, although we did not detect appressorium-specific expression of the metallothioneins of $M$. grisea.

\section{Alternate RNA forms.}

Alternate cDNA species were found. The most common type of alternative splice was the splice/nonsplice as illustrated in forms 4 through 6 of the gene shown in Figure 3. Several examples of alternative use of the $5^{\prime}$ splice site were observed, including that illustrated by form 3 RNA. Examples of likely alternate choices for transcription initiation or termination sites were also observed (not shown). Exon sizes as short as 6 nt were also detected in comparisons with genomic DNA (not shown). In $N$. crassa, exons as short as 3 nt have been detected (Edelmann and Staben 1994). Such small exons are difficult to predict based on sequence alone, since parameters that can be used to help predict coding regions, such as codon bias, are not useful for such a small exon size.

\section{EST and genome annotation.}

The identification of genes encoding very small polypeptides and alternate RNA transcripts demonstrates the importance of EST and other RNA sequence data in helping to identify genes and predict their proper coding regions. Genome sequence alone, although perhaps the most valuable resource, 
requires substantial additional biological data to improve annotation and prediction of protein coding regions. Thus, intron identification and identification of the $5^{\prime}$ and $3^{\prime}$ ends of transcripts is an essential contribution of EST data. There are relatively few genes with functionally verified intron/exon boundaries, and this has limited the training of algorithms for fungal gene prediction. Alignments of ESTs with genomic sequence are viewable on the Broad Institute's Calhoun genome browser, and this alignment has defined over 1,600 introns that will help refine the model for intron structure and assist in annotation of protein coding regions for $\mathrm{M}$. grisea and other fungal genomes.

We found that trimming single-pass sequence data based on the typically used quality scores was more stringent than trimming based on matches to genomic sequence. Once genome sequences for an organism become available, a re-analysis of previously determined ESTs that have been trimmed based on quality scores could prove useful in extending sequences, to help define intron and exon boundaries.

In summary, we have characterized a set of over 28,000 EST sequences that provide insight into gene content and gene structure of $M$. grisea. Of significance is the discovery of an apparently novel family of genes encoding small polypeptides. Expression patterns for abundantly expressed genes revealed tissue-specific and growth condition-specific patterns of gene expression that will help to guide functional analysis of the genes defined by EST analysis.

\section{MATERIALS AND METHODS}

\section{Library construction and DNA sequencing.}

The ap library was produced from germinated conidia of mating type Mat1-2 strain 70-15 (Chao and Ellingboe 1991; Leung et al. 1988) that had been incubated on the surface of Gelbond film (FMC Inc., Rockland, ME, U.S.A.) for 5 to $8 \mathrm{~h}$. A library (mk) was similarly produced from the NN95 pmkl mutant (Xu and Hamer 1996) that was produced in the Guy11 (Mat1-2) strain background. To produce the cs library, conidia were harvested from oatmeal agar cultures of strain Guy11 and RNA was directly extracted from conidia. Flask cultures were inoculated with one-square-centimeter plugs from culture plates. Strain Guy11 was grown in complete medium (Beckerman and Ebbole 1996) for 2 days at room temperature in flasks with shaking at $150 \mathrm{rpm}$, was harvested by filtration, was washed with the appropriate medium, was blended in a Waring blender $(2 \times 15 \mathrm{~s})$, and was reinoculated into complete medium for an additional $24 \mathrm{~h}$ prior to harvesting for RNA preparation, to produce the $\mathrm{cm}$ library. Cells were transferred to minimal medium lacking the nitrogen source for $6 \mathrm{~h}$, to produce the Guy11 ns library. Strain 70-15 was grown similarly in minimal medium (Beckerman and Ebbole 1996) to produce the minimal medium library. A cDNA library from $M$. grisea strains grown on rice cell wall material was a gift from S.-C. Wu (University of Georgia, Athens, U.S.A.). M. grisea Mat1-2 $\mathrm{CP} 987$ was grown for 5 days at $23^{\circ} \mathrm{C}$ with rotary shaking (100 $\mathrm{rpm}$ ) in the dark in Vogel's minimal medium salts (Davis and De Serres 1970) containing $0.5 \%$ isolated rice cell walls as the carbon source. Strains 4091-5-8 (Mat1.2) and 4136-4-3 (Mat11) were coinoculated onto Whatman No. 1 filter paper on oatmeal agar medium and were grown for 3 days at $25^{\circ} \mathrm{C}$. Plates were transferred to $21^{\circ} \mathrm{C}$ with constant light, and perithecia with asci and ascospores were produced after 15 days. The tissue containing perithecia was excised from the filter paper for mRNA isolation. Strain P1.2 (Mat1-2) is a progeny derived from sib matings from progeny of parent strains that were obtained from infected rice in Thailand (M.-H. Lebrun, personal communication), and a cDNA library was provided as a gift from Bayer Crop Science SA (Lyon, France). The P1.2 cDNA library was produced from RNA isolated from combined cultures grown with different stress conditions, and sequence analysis of a fraction of the library was performed by Bayer ( $R$. Beffa, unpublished data). The most abundant 96 genes identified from this analysis were mixed and prepared as a probe for hybridization to colony blots of the library. Nonhybridizing clones were picked into microtitre dishes and were provided to us as the subtracted (su) library.

Total RNA was extracted from harvested $M$. grisea cultures using phenol/chloroform extraction (Madi et al. 1994). Poly A+ mRNA was isolated with the Stratagene Poly(A) Quik mRNA isolation kit (Stratagene, La Jolla, CA, U.S.A.). cDNA was prepared and cloned using the unidirectional lambda ZAPII vector kit (Stratagene), utilizing EcoRI and XhoI restriction sites. The oligo-dT primer contained an XhoI restriction site, and after cloning, this site is adjacent to the $\mathrm{T} 7$ primer site of the vector. cDNA clones were excised as pBluescriptII (SK-) plasmids in SOLR (Stratagene) Escherichia coli host cells. Cells were plated on X-gal plates, and $\beta$-galactosidasenegative colonies were picked to 384-well microtitre dishes using a Qbot (Genetix, New Milton, Hampshire, U.K.). Clones were rearrayed into 96 -well plates for sequencing.

Templates were produced by either alkaline lysis or with AmpliPhi template amplification technology (Amersham Bioscience, Buckinghamshire, U.K.). Sequencing reactions were performed in 96-well plates, using T3 primer (corresponding to the transcript $5^{\prime}$ end) and were analyzed using ABI 377 DNA sequencers in the Laboratory for Functional Genomics (Texas A\&M University, College Station, U.S.A.).

\section{Sequence processing.}

The ABI 377 chromatogram files were processed using the PhredPhrap script that uses Phred (Version 0.990722) (Ewing and Green 1998) to call bases and provide quality scores and Crossmatch to mask vector sequences. The output sequences of Phred and Crossmatch were processed by either trimming according to default Phred value (0.05) or based on blastn alignment to the Magnaporthe genome sequence (Broad Institute Center for Genome Research (e value $=\mathrm{e}^{-20}$ ). Vector sequences identified by Crossmatch were removed. In addition, a computer program was written to search a table of vector sequence variants at the beginning of each EST to identify and trim likely vector sequences that were missed by Crossmatch. For ESTs that were trimmed based on matches to the genome sequence, runs of polyA or polyT at the trim site were replaced by five A or T residues to indicate that the EST sequence contained apparent polyA sequences in the cDNA clones. Approximately $78 \%$ of sequencing reactions produced high quality sequences from inserts, and $97 \%$ of sequences were $>100 \mathrm{nt}$ in length. The average high-quality trimmed sequence length based on Phred scores ranged from 261 to $423 \mathrm{nt}$ for the different libraries, and the average sequence length based on alignment to genome sequence ranged from 358 to $593 \mathrm{nt}$. The sequence lengths of ESTs trimmed based on Phred quality scores and genome sequence alignments were compared, and the longer sequences were used. All ESTs were searched against the GenBank nonredundant amino acid reference library (April 2003), and the top scoring hit was added to the comment line before depositing processed sequences in GenBank. Chromatogram files for all gels are available from the Texas A\&M web site. Chromat files have also been distributed for independent analysis available at the MGOS (Magnaporthe griseal Oryzae sativa) database.

Sequences were assembled into contigs using StackPack 2.1 software (Electronic Genetics PTY, Ltd.). StackPack 2.0 uses cluster_d2 (Burke et al. 1999) followed by Phrap to generate clusters and consensus sequences. These and other $M$. grisea 
EST sequences have also been analyzed by The Institute for Genomic Research and are available online from the TIGR Rice Blast Gene Index and the Center for the Functional Genomics of Microbial Eukaryotes (COGEME) web sites.

\section{Statistical methods.}

We calculated an $R$ statistic (Stekel et al. 2000) for each cluster as a measure to detect clusters that are statistically differentially expressed across all eight libraries. The su library was removed from this analysis. All eight remaining libraries were large enough and fit the criteria described by Stekel and associates (2000) to qualify for analysis of gene expression across multiple cDNA libraries. A total of 207 clusters were identified that have an $R$ value of 14 or greater, which corresponds to a true positive rate of $99.99 \%$.

Hierarchical clustering analysis (Eisen et al. 1998) using standard correlation was performed on the 207 differentially expressed clusters, using the commercial software package Genespring. We analyzed the relative expression level of all genes across the eight libraries, as well as on the eight libraries across all genes. As a result, a hierarchical relationship of the 207 genes and a hierarchical relationship of the eight libraries were generated.

\section{Assignment of GO terms to clusters.}

The unigene set of EST clusters and singletons were translated in six frames and were used to search the InterPro database (version 7) (Mulder et al. 2003), using the iprscan search tool provided by the InterPro database project. InterPro entries that were assigned to EST sequences were translated to terms from the GO project (Ashburner et al. 2000), using a mapping file provided with InterPro. To identify putative homologous genes, a set of 32,309 manually curated protein sequences were downloaded from the GO database and were used as a blast database for annotating the EST sequences. A blastx search was performed using this database, and GO terms from the top hit that also had an e value greater than $\mathrm{e}^{-30}$ were transferred to the ESTs. GO terms from the InterPro and blastx searches were merged and loaded into a GO database, available at the North Carolina State University Fungal Genomics Laboratory database for $M$. grisea.

\section{ACKNOWLEDGMENTS}

This work was supported by United States Department of Agriculture Initiative for Future Agriculture and Food Systems grant 00-52100-9682. We thank R. Hamer and E. Kolomiets for assistance with programs used in EST analysis and submission. We also thank L. Budde for assistance with statistical analysis and P. Bobrowicz for cDNA library construction.

\section{LITERATURE CITED}

Ashburner, M., Ball, C. A., Blake, J. A., Botstein, D., Butler, H., Cherry, J. M., Davis, A. P., Dolinski, K., Dwight, S. S., Eppig, J. T., Harris, M. A., Hill, D. P., Issel-Tarver, L., Kasarskis, A., Lewis, S., Matese, J. C., Richardson, J. E., Ringwald, M., Rubin, G. M., and Sherlock, G. 2000. Gene ontology: Tool for the unification of biology. Nature Genetics 25:25-29.

Beckerman, J. L., and Ebbole, D. J.1996. MPG1, a gene encoding a fungal hydrophobin of Magnaporthe grisea, is involved in surface recognition. Mol. Plant-Microbe Interact. 9:450-456.

Berbee, M. L., and Taylor, J. W. 2001. Fungal molecular evolution: Gene trees and geologic time. Pages 229-245 in: The Mycota: A Comprehensive Treatise on Fungi as Experimental Systems for Basic and Applied Research. Vol. VII. Systematics and Evolution. D. J. McLaughlin, E. G. McLaughlin, and P. A. Lemke, eds. SpringerVerlag, New York.

Burke, J., Davison, D., and Hide, W. 1999. d2_cluster: A validated method for clustering EST and full-length cDNA sequences. Genome Res. 9:1135-1142.
Chao, C. C. T., and Ellingboe, A. H. 1991. Selection for mating competence in Magnaporthe grisea pathogenic to rice. Can. J. Bot. 69:2130-2134.

Davis, R. H., and De Serres, F. J. 1970. Genetic and microbial research techniques for Neurospora crassa. Meth. Enzymol. 17A:79-143.

Dean, R. A. 1997. Signal pathways and appressorium morphogenesis. Ann. Rev. Phytopathol. 35:211-234.

Dioh, W., Tharreau, D., Notteghem, J. L., Orbach, M., and Lebrun, M.-H. 2000. Mapping of avirulence genes in the rice blast fungus, Magnaporthe grisea, with RFLP and RAPD markers. Mol. Plant-Microbe Interact. 13:217-227.

Edelmann, S. E., and Staben, C. 1994. A statistical analysis of sequence features within genes from Neurospora crassa. Exp. Mycol. 18:70-81.

Eisen, M. B., Spellman, P. T., Brown, P. O., and Botstein, D. 1998. Cluster analysis and display of genome-wide expression patterns. Proc. Natl. Acad. Sci. U.S.A. 95:14863-14868.

Ewing, B., and Green, P. 1998. Base-calling of automated sequencer traces using phred. II. Error probabilities. Genome Res. 8:186-194.

Galagan, J. E., Calvo, S. E., Borkovich, K. A., Selker, E. U., Read, N. D., Jaffe, D., FitzHugh, W., Ma, L. J., Smirnov, S., Purcell, S. Rehman, B., Elkins, T., Engels, R., Wang, S. G., Nielsen, C. B., Butler, J., Endrizzi, M., Qui, D. Y., Ianakiev, P., Pedersen, D. B., Nelson, M. A., WernerWashburne, M., Selitrennikoff, C. P., Kinsey, J. A., Braun, E. L., Zelter, A., Schulte, U., Kothe, G. O., Jedd, G., Mewes, W., Staben, C., Marcotte, E., Greenberg, D., Roy, A., Foley, K., Naylor, J., StabgeThomann, N., Barrett, R., Gnerre, S., Kamal, M., Kamvysselis, M., Mauceli, E., Bielke, C., Rudd, S., Frishman, D., Krystofova, S., Rasmussen, C., Metzenberg, R. L., Perkins, D. D., Kroken, S., Cogoni, C., Macino, G., Catcheside, D., Li, W. X., Pratt, R. J., Osmani, S. A. DeSouza, C. P. C., Glass, L., Orbach, M. J., Berglund, J. A., Voelker, R., Yarden, O., Plamann, M., Seller, S., Dunlap, J., Radford, A., Aramayo, R., Natvig, D. O., Alex, L. A., Mannhaupt, G., Ebbole, D. J., Freitag, M., Paulsen, I., Sachs, M. S., Lander, E. S., Nusbaum, C., and Birren, B. 2003. The genome sequence of the filamentous fungus Neurospora crassa. Nature 422:859-868.

Howard, R. J., and Valent, B. 1996. Breaking and entering: Host penetration by the fungal rice blast pathogen Magnaporthe grisea. Ann. Rev. Microbiol. 50:491-512.

Hwang, C. S., and Kolattukudy, P. E. 1995. Isolation and characterization of genes expressed uniquely during appressorium formation by Colle totrichum gloeosporioides conidia induced by the host surface wax. Mol. General Genet. 247:282-294.

Irie, T., Matsumura, H., Terauchi, R., and Saitoh, H. 2003. Serial analysis of gene expression (SAGE) of Magnaporthe grisea: Genes involved in appressorium formation. Mol. Genet. Genomics 270:181-189.

Kershaw, M. J., Wakley, G., and Talbot, N. J. 1998. Complementation of the Mpg1 mutant phenotype in Magnaporthe grisea reveals functional relationships between fungal hydrophobins. EMBO (Eur. Mol. Biol. Organ.) J. 17:3838-3849

Kihara, J., Sato, A., Okajima, S., and Kumagai, T. 2001. Molecular cloning, sequence analysis and expression of a novel gene induced by nearUV light in Bipolaris oryzae. Mol. Genet. Genomics 266:64-71.

Kim, S., Ahn, I.-P., and Lee, Y.-H. 2001. Analysis of genes expressed during rice-Magnaporthe grisea interactions. Mol. Plant-Microbe Interact. 14:1340-1346.

Kulkarni, R. D., and Dean, R. A. 2004. Identification of proteins that interact with two regulators of appressorium development, adenylate cyclase and cAMP-dependent protein kinase A, in the rice blast fungus Magnaporthe grisea. Mol. General Genet. 270:497-508.

Laugé, R., and De Wit, P. J. G. M. 1998. Fungal avirulence genes: Structure and possible functions. Fungal Genet. Biol. 24:285-297.

Leung, H., Borromeo, E. S., Bernardo, M. A., and Notteghem, J. L. 1988. Genetic-analysis of virulence in the rice blast fungus Magnaporthe grisea. Phytopathology 78:1227-1233.

Lugones, L. G., Wosten, H. A. B., Birkenkamp, K. U., Sjollema, K. A., Zagers, J., and Wessels, J. G. H. 1999. Hydrophobins line air channels in fruiting bodies of Schizophyllum commune and Agaricus bisporus. Mycol. Res. 103:635-640.

Madi, L., Ebbole, D. J., White, B. T., and Yanofsky, C. 1994. Mutants of Neurospora crassa that alter gene-expression and conidia development. Proc. Natl. Acad. Sci. U.S.A. 91:6226-6230.

McNally, M. T., and Free, S. J. 1988. Isolation and characterization of a Neurospora glucose-repressible gene. Curr. Genet. 14:545-551.

Mulder, N. J., Apweiler, R., Attwood, T. K., Bairoch, A., Barrell, D., Bateman, A., Binns, D., Biswas, M., Bradley, P., Bork, P., Bucher, P., Copley, R. R., Courcelle, E., Das, U., Durbin, R., Falquet, L., Fleischmann, W., Griffiths-Jones, S., Haft, D., Harte, N., Hulo, N., Kahn, D., Kanapin, A., Krestyaninova, M., Lopez, R., Letunic, I., Lonsdale, D., Silventoinen, V., Orchard, S. E., Pagni, M., Peyruc, D., Ponting, C. P., Selengut, J. D., Servant, F., Sigrist, C. J. A., Vaughan, R., and Zdobnov, E. 
M. 2003. The InterPro database, 2003 brings increased coverage and new features. Nucleic Acids Res. 31:315-318.

Munger, K., Germann, U. A., and Lerch, K. 1985. Isolation and structural organization of the Neurospora crassa copper metallothionein gene. EMBO (Eur. Mol. Biol. Organ.) J. 4:2665-2668.

Nelson, M. A., Kang, S. C., Braun, E. L., Crawford, M. E., Dolan, P. L., Leonard, P. M., Mitchell, J., Armijo, A. M., Bean, L., Blueyes, E., Cushing, T., Errett, A., Fleharty, M., Gorman, M., Judson, K., Miller, R., Ortega, J., Pavlova, I., Perea, J., Todisco, S., Trujillo, R., Valentine, J., Wells, A., Werner Washburne, M., Yazzie, S., and Natvig, D. O. 1997. Expressed sequences from conidial, mycelial, and sexual stages of Neurospora crassa. Fungal Genet. Biol. 21:348-363.

Shen, W. C., Bobrowicz, P., and Ebbole, D. J. 1999. Isolation of pheromone precursor genes of Magnaporthe grisea. Fungal Genet. Biol. 27:253-263.

Stekel, D. J., Git, Y., and Falciani, F. 2000. The comparison of gene expression from multiple cDNA libraries. Genome Res. 10:2055-2061.

Talbot, N. J., Ebbole, D. J., and Hamer, J. E. 1993. Identification and characterization of $\mathrm{Mpg} 1$, a gene involved in pathogenicity from the rice blast fungus Magnaporthe grisea. Plant Cell 5:1575-1590.

Talbot, N. J., Kershaw, M. J., Wakley, G. E., deVries, O. M. H., Wessels, J. G. H., and Hamer, J. E. 1996. MPG1 encodes a fungal hydrophobin involved in surface interactions during infection-related development of Magnaporthe grisea. Plant Cell 8:985-999.

Trail, F., Xu, J. R., San Miguel, P., Halgren, R. G., and Kistler, H. C. 2003 Analysis of expressed sequence tags from Gibberella zeae (anamorph Fusarium graminearum). Fungal Genet. Biol. 38:187-197.

Tucker, S .L., and Talbot, N. J. 2001. Surface attachment and pre-penetration stage development by plant pathogenic fungi. Ann. Rev. Phytopathol. 39:385-417.

Valent, B., and Chumley, F. G. 1991. Molecular genetic analysis of the rice blast fungus, Magnaporthe grisea. Ann. Rev. Phytopathol. 29:443-467.
Wosten, H. A. B., van Wetter, M. A., Lugones, L. G., van der Mei, H. C Busscher, H. J., and Wessels, J. G. H. 1999. How a fungus escapes the water to grow into the air. Curr. Biol. 9:85-88.

$\mathrm{Xu}$, J. R., and Hamer, J. E. 1996. MAP kinase and cAMP signaling regulate infection structure formation and pathogenic growth in the rice blast fungus Magnaporthe grisea. Genes Dev. 10:2696-2706.

Xue, C. Y., Park, G., Choi, W. B., Zheng, L., Dean, R. A., and Xu, J. R. 2002. Two novel fungal virulence genes specifically expressed in appressoria of the rice blast fungus. Plant Cell 14:2107-2119.

Zhang, X., Yang, Z., Khan, S. I., Horton, J. R., Tamaru, H., Selker, E. U., and Cheng, X. D. 2003. Structural basis for the product specificity of histone lysine methyltransferases. Mol. Cell 12:177-185.

\section{AUTHOR-RECOMMENDED INTERNET RESOURCES}

Broad Institute $M$. grisea genome database: www.broad.mit.edu/annotation/fungi/magnaporthe

The Consortium for the Functional Genomics of Microbial Eukaryotes database: cogeme.ex.ac.uk

Genespring commercial software: www.silicongenetics.com

The Institute for Genomic Research (TIGR) M. grisea gene indices: www.tigr.org/tdb/tgi/mggi

National Science Foundation MGOS (Magnaporthe grisea/Oryzae sativa) database: www.mgosdb.org, Magnaporthe grisea Oryzae sativa database

The North Carolina State University Fungal Genomics Laboratory GO annotation database for $M$. grisea: www.fungalgenomics.ncsu.edu/cgi-bin/gocgi/go.cgi

Texas A\&M University Chromat files directory: plpa2linux.tamu.edu/Chromat.html

Texas A\&M University stackPACK clustering system: plpa2linux.tamu.edu/stackpack 